\title{
Effect of Strain Variations on Lassa Virus Z Protein-Mediated Human RIG-I Inhibition
}

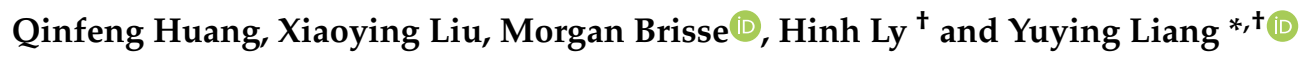 \\ Department of Veterinary and Biomedical Sciences, College of Veterinary Medicine, University of Minnesota, \\ St Paul, MN 55108, USA; huangq@umn.edu (Q.H.); liux2725@umn.edu (X.L.); briss049@umn.edu (M.B.); \\ hly@umn.edu (H.L.) \\ * Correspondence: liangy@umn.edu; Tel.: +1-612-625-3376; Fax: +1-612-625-0204 \\ + These authors co-supervised this work.
}

Received: 9 July 2020; Accepted: 16 August 2020; Published: 19 August 2020

check for updates

\begin{abstract}
Mammarenaviruses include several known human pathogens, such as the prototypic lymphocytic choriomeningitis virus (LCMV) that can cause neurological diseases and Lassa virus (LASV) that causes endemic hemorrhagic fever infection. LASV-infected patients show diverse clinical manifestations ranging from asymptomatic infection to hemorrhage, multi-organ failures and death, the mechanisms of which have not been well characterized. We have previously shown that the matrix protein Z of pathogenic arenaviruses, including LASV and LCMV, can strongly inhibit the ability of the innate immune protein RIG-I to suppress type I interferon (IFN-I) expression, which serves as a mechanism of viral immune evasion and virulence. Here, we show that $Z$ proteins of diverse LASV isolates derived from rodents and humans have a high degree of sequence variations at their $\mathrm{N}$ - and C-terminal regions and produce variable degrees of inhibition of human RIG-I (hRIG-I) function in an established IFN- $\beta$ promoter-driven luciferase (LUC) reporter assay. Additionally, we show that Z proteins of four known LCMV strains can also inhibit hRIG-I at variable degrees of efficiency. Collectively, our results confirm that Z proteins of pathogenic LASV and LCMV can inhibit hRIG-I and suggest that strain variations of the $Z$ proteins can influence their efficiency to suppress host innate immunity that might contribute to viral virulence and disease heterogeneity.
\end{abstract}

Keywords: Lassa virus; LCMV; arenavirus; sequence variations; Z protein; RIG-I; innate immunity; immune evasion

\section{Introduction}

Lassa fever is an acute viral illness that is endemic in several western African nations, where it is estimated to infect about 300,000 to 500,000 people annually and to cause 5000 deaths yearly [1]. Currently there are no FDA-approved vaccines and limited treatment options for Lassa fever. The disease is caused by Lassa virus (LASV), a zoonotic RNA virus in the family of Arenaviridae with a natural reservoir in the local rodents Mastomys natalensis, Mastomys erythroleucus, and African wood mouse Hylomyscus pamfi [2-4]. Most human infections are asymptomatic. However, about $20 \%$ of the cases develop mild to severe symptoms that may lead to hemorrhage, multi-organ failure, and death [5]. The general case-fatality rate is relatively low at approximately $1 \%$, but it can be as high as $15 \%$ among hospitalized patients and $\sim 50 \%$ in occasional epidemics [6-8]. The reasons for this diverse disease heterogeneity are unknown but can be attributed to several factors, such as co-infection with other pathogens, host's pre-existing immunity, the amount of viral inoculum, and the relatively high genetic diversity among the LASV isolates.

LASV isolates found in different geographic and host origins are highly diverse in sequences and are phylogenetically classified into four major lineages or clusters (I-IV) with $25 \%$ and $32 \%$ sequence 
variations in the viral genomic small (S) and large (L) segments, respectively [9,10]. The L and S genomic segments encode four known viral gene products in opposite orientations [11]. The L segment encodes the large polymerase protein $\mathrm{L}$ of $\sim 200 \mathrm{kDa}$ in size and a small matrix protein $\mathrm{Z}$ of $\sim 15 \mathrm{KDa}$. The $S$ segment encodes the nucleoprotein $\mathrm{NP}(\sim 65 \mathrm{kDa})$ and the glycoprotein precursor complex (GPC) ( 75 kDa). All four of these viral proteins have been shown to be absolutely essential for viral replication and disease pathogenesis in vitro and in vivo (reviewed in [12]). The viral GPC complex mediates viral entry through binding to host cellular receptor and mixing of the viral lipid membrane with that of the cellular endosome in order to release the viral genomic materials into the cytoplasm for viral genomic transcription and replication by the L polymerase and the NP protein (reviewed in [13]). In addition, the viral matrix protein $Z$ has been shown to negatively regulate viral RNA synthesis in order to orchestrate virion assembly and budding at the infected cell surface (reviewed in [14]).

Besides mediating viral genomic RNA encapsidation into the viral ribonucleoprotein (RNP) complex as well as viral RNA transcription and replication, NP has also been shown by us and others to participate in the suppression of IFN-I through its exoribonuclease (RNase) activity to degrade double-stranded immunostimulatory RNA (dsRNA) in order to allow the virus to evade the host immune sensing [15,16], reviewed in [17]). We have also shown that the $Z$ protein of pathogenic arenaviruses including LASV can inhibit IFN-I production by directly binding to and inhibiting the innate immune proteins RIG-I and MDA5, collectively known as the RIG-I-like receptors (RLRs), and in doing so, it acts as a potential viral virulent factor [18].

Various animal models have been developed to characterize the degrees of viral virulence and disease pathology mediated by LASV infection (reviewed in [19]). Accumulating evidence has suggested that different LASV isolates can mediate differential degrees of virulence and disease pathogenesis in animal models. The LASV strains isolated from Liberian patients have been shown to cause different degrees of virulence in inbred guinea pigs, although viral virulence in guinea pigs is poorly correlated with the clinical outcomes in humans [20]. A recent study showed that different LASV clinical isolates derived from a patient who suffered from a lethal infection and one from a non-lethal outcome exhibited differential degrees of virulence in the Stat1-/- mouse model that appeared to be consistent with the clinical outcomes observed in the human patients [21]. Additionally, Safronetz and colleagues showed that LASV Soromba-R strain isolated from rodents in Mali was less pathogenic in non-human primates (NHPs) than the human LASV isolates Josiah and Z-132 [22]. We hypothesize that the wide degree of sequence diversity among the LASV isolates may partly account for the differential disease manifestations and pathogenicity. How Lassa viral strain or isolate variations affect viral replication, virulence, immune responses, and pathogenesis have not been well characterized.

In the current study, we aligned the sequences of the Z protein of different LASV strains and isolates available in GenBank, which showed significant sequence variations at their N- and C-terminal regions. Phylogenetic analysis of the amino acid sequences of these $\mathrm{Z}$ proteins shows that they form the same four major clusters as have previously been described for the LASV NP and whole viral genomic nucleotide sequences $[9,10]$. We chemically synthesized and expressed $20 \mathrm{Z}$ proteins of LASV isolates from human patients and rodent reservoirs, and analyzed their functional activities to inhibit human RIG-I (hRIG-I) by using an established IFN- $\beta$ promoter-driven luciferase (LUC) reporter assay [18]. Our data show that all tested LASV Z proteins can inhibit hRIG-I, which is consistent with our previous report [18], and that those from human viral isolates are on average slightly stronger inhibitors of hRIG-I than those of the rodent origin. In addition, we showed that Z proteins of four LCMV strains inhibit hRIG-I at different efficiencies. Collectively, our results confirm that Z proteins of LASV and LCMV can strongly inhibit hRIG-I and suggest that strain variations of the $Z$ protein can potentially impact virus-mediated host immune modulation, viral virulence, and disease pathogenesis. 


\section{Materials and Methods}

\subsection{Sequence Analysis}

The full-length amino acid sequences of $\mathrm{Z}$ proteins from diverse LASV isolates and LCMV strains were obtained from the GenBank database and were analyzed via multiple protein alignment and phylogenetic tree using the MacVector Software (MacVector, Inc., Apex, NC, USA).

\subsection{Cells and Plasmids}

Human kidney epithelial 293T cells were grown in Dulbecco's modified Eagle's medium (DMEM) supplemented with $10 \%$ fetal bovine serum (FBS) and $50 \mu \mathrm{g} / \mathrm{mL}$ penicillin-streptomycin antibiotics.

Mammalian expression plasmids (pCAGGS) that contain the C-terminally hemagglutinin (HA)-tagged Pichinde virus (PICV), LASV (Josiah), and LCMV (Armstrong) Z proteins were described in our previous publications $[18,23]$. Expression plasmids for other C-terminally HA-tagged LASV and LCMV Z proteins were similarly constructed using chemically synthesized genes by Genewiz (South Plainfield, NJ, USA) based on the primary sequence obtained from the GenBank database. The list of all $\mathrm{Z}$ expression plasmids used in this study is shown in Table 1. The mammalian expression plasmid pEF-Flag-RIG-I-N encoding the N-terminal activation domain of the hRIG-I protein that is fused to a C-terminal FLAG tag was a kind gift of Takashi Fujita (Kyoto University, Japan).

Table 1. List of the $\mathrm{Z}$ protein sequences and their expression plasmids used in this study.

\begin{tabular}{|c|c|c|c|c|c|c|}
\hline $\begin{array}{l}\text { Z Plasmid } \\
\text { Name }\end{array}$ & $\begin{array}{l}\text { Accession } \\
\text { Number }\end{array}$ & Virus & Isolate/Strain & Host Species & $\begin{array}{l}\text { Country } \\
\text { Isolated }\end{array}$ & $\begin{array}{l}\text { LASV } \\
\text { Cluster }\end{array}$ \\
\hline MN444 & NP_694871.1 & LASV & Josiah & Homo sapiens & Sierra Leone & IV \\
\hline MN446 & AAO59508.1 & LASV & AV & Homo sapiens & Ivory Coast & IV \\
\hline MN447 & AHC95549.1 & LASV & Soromba-R & Mastomys natalensis & Mali & IV \\
\hline MN496 & ADU56644.1 & LASV & BA366 & Mastomys natalensis & Guinea & IV \\
\hline MN515 & AIT17260.1 & LASV & G2295 & Homo sapiens & Sierra Leone & IV \\
\hline MN516 & AIT17272.1 & LASV & G2363 & Homo sapiens & Sierra Leone & IV \\
\hline MN517 & AIT17330.1 & LASV & G2903 & Homo sapiens & Sierra Leone & IV \\
\hline MN518 & AIT17382.1 & LASV & G3229 & Homo sapiens & Sierra Leone & IV \\
\hline MN519 & AIT17386.1 & LASV & G3234 & Homo sapiens & Sierra Leone & IV \\
\hline MN520 & AIT17602.1 & LASV & LASV049 & Homo sapiens & Nigeria & II \\
\hline MN521 & AIT17692.1 & LASV & LASV274 & Homo sapiens & Nigeria & II \\
\hline MN522 & AIT17760.1 & LASV & LASV989 & Homo sapiens & Nigeria & II \\
\hline MN523 & AIT17768.1 & LASV & LASV991 & Homo sapiens & Nigeria & II \\
\hline MN524 & AIT17780.1 & LASV & LASV1000 & Homo sapiens & Nigeria & II \\
\hline MN525 & AIT17800.1 & LASV & LM032 & Mastomys natalensis & Sierra Leone & IV \\
\hline MN526 & AIT17808.1 & LASV & LM395 & Mastomys natalensis & Sierra Leone & IV \\
\hline MN527 & AIT17818.1 & LASV & LM774 & Mastomys natalensis & Sierra Leone & IV \\
\hline MN528 & AIT17804.1 & LASV & LM222 & Mastomys natalensis & Sierra Leone & IV \\
\hline MN529 & AIT17830.1 & LASV & LM779 & Mastomys natalensis & Sierra Leone & IV \\
\hline MN530 & AIT17842.1 & LASV & Z0948 & Mastomys natalensis & Sierra Leone & IV \\
\hline MN531 & АНC95547.1 & LASV & Bamba-R114 & Mastomys natalensis & Mali & IV \\
\hline MN445 & ABU39910 & PICV & $\begin{array}{c}\text { Munchique } \\
\text { CoAn4763 } \\
\text { P2/P18 isolate }\end{array}$ & Cavia porcellus & lab strain & \\
\hline
\end{tabular}


Table 1. Cont

\begin{tabular}{|c|c|c|c|c|c|c|}
\hline $\begin{array}{l}\text { Z Plasmid } \\
\text { Name }\end{array}$ & Accession & Virus & Isolate/Strain & Host Species & $\begin{array}{l}\text { Country } \\
\text { Isolated }\end{array}$ & $\begin{array}{l}\text { LASV } \\
\text { Cluster }\end{array}$ \\
\hline MN448 & P18541.3 & LCMV & Armstrong & Homo sapiens & lab strain & \\
\hline MN915 & CAA10342 & LCMV & MX & MaTu cell line & lab strain & \\
\hline MN916 & AAD03395.1 & LCMV & WE & Homo sapiens & lab strain & \\
\hline MN917 & ACV72580 & LCMV & 810935 & Homo sapiens & USA & \\
\hline
\end{tabular}

\subsection{RIG-I-Induced IFN $\beta$-Promoter-Dependent LUC Reporter Assay}

293T cells seeded into 12-well plates and grown overnight in the $\mathrm{CO}_{2}$ tissue-culture incubator were transfected with either an empty vector or individual $\mathrm{Z}$ expression vector at different concentrations (125 ng, $250 \mathrm{ng}, 500 \mathrm{ng}$, or $1000 \mathrm{ng}$ ), together with $100 \mathrm{ng}$ of pEF-Flag-RIG-I-N (expressing the $N$-terminal activation domain of the hRIG-I), $100 \mathrm{ng}$ of IFN $\beta$-LUC vector, which expresses the firefly luciferase (Fluc) reporter gene from the DNA regulatory element of the IFN- $\beta$ promoter, and $50 \mathrm{ng}$ of a $\beta$-galactosidase $(\beta$-Gal)-expressing plasmid for the purpose of normalization for plasmid DNA transfection and RNA polymerase II transcription efficiency. Transfected cell lysates were prepared at $24 \mathrm{~h}$ post-transfection. Fluc reporter gene expressions were normalized to the $\beta$-Gal gene-expression values as previously described [15]. Each plasmid transfection was conducted in triplicate and repeated in at least two independent experiments. Statistical significance between two groups was determined using the two-tail unpaired Student's t-test of GraphPad Prism 6 software.

\subsection{Western Blot}

Cell lysates were separated by 15\% sodium dodecyl sulfate (SDS)-polyacrylamide gel and transferred onto nitrocellulose membranes. After blocking in 5\% nonfat powdered milk in Tris- $\mathrm{HCl}$ buffer (TBS), the membrane was incubated with anti-HA and anti-actin monoclonal antibodies (Sigma, St. Louis, MO, USA), washed three times with TBS (50 mM Tris- $\mathrm{HCl}, \mathrm{pH}$ 7.4), and probed with HRP-conjugated goat anti-mouse antibody (R \& D Systems). After washing with TBS buffer with $0.05 \%$ Tween 20, the membrane was analyzed by myECL (Thermo Scientific, Waltham, MA, USA) using the enhanced chemiluminescence (ECL) reaction in the Western Chemiluminescent HRP substrate (Millipore Sigma, Burlington, MA, USA).

\section{Results}

\subsection{Sequence Alignment of Z Proteins from Different LASV Strains and Isolates}

We obtained LASV Z protein sequences from the GenBank database, including those of the Josiah [24], AV, NL, and CSF [25], Macenta and Z148 isolates (deposited by the the Viral Sequencing Group at Lawrence Livermore, 2004), clinical isolates in Nigeria [26], rodent reservoir samples in subSaharan Mali [27], and 200 sequences from clinical and rodent reservoir samples deposited by the Viral Hemorrhagic Fever Consortium [10]. After removing all identical sequences, 100 unique LASV $\mathrm{Z}$ protein sequences were aligned (Figure $1 \mathrm{~A}$ ), which showed as high as $33 \%$ sequence variations. Sequence variations occur mostly in the flexible N- and C-terminal domains (NTD and CTD) of Z proteins, while the central RING domain is highly conserved. Phylogenetic analysis (Figure 1B) showed that these $\mathrm{Z}$ proteins clustered into the same four major clusters as previously reported based on the LASV NP nucleotide [9] and complete viral genomic sequences [10]. Cluster I included the LASV Pinneo isolate that was originally isolated from an American patient in Nigeria. Clusters II and III consisted of LASV clinical isolates found in Nigeria. Cluster IV included clinical and rodent isolates found in other regions West of Nigeria (Sierra Leone, Guinea, Liberia, Côte d'Ivoire, Mali). Also included in cluster IV were 11 sequences from rodent isolates found in Sierra Leone and Mali 
(Figure 1B, shaded in blue), which clustered together with human viral isolates and did not form species-specific clusters, consistent with previous finding based on LASV nucleotide sequences [10].

A.

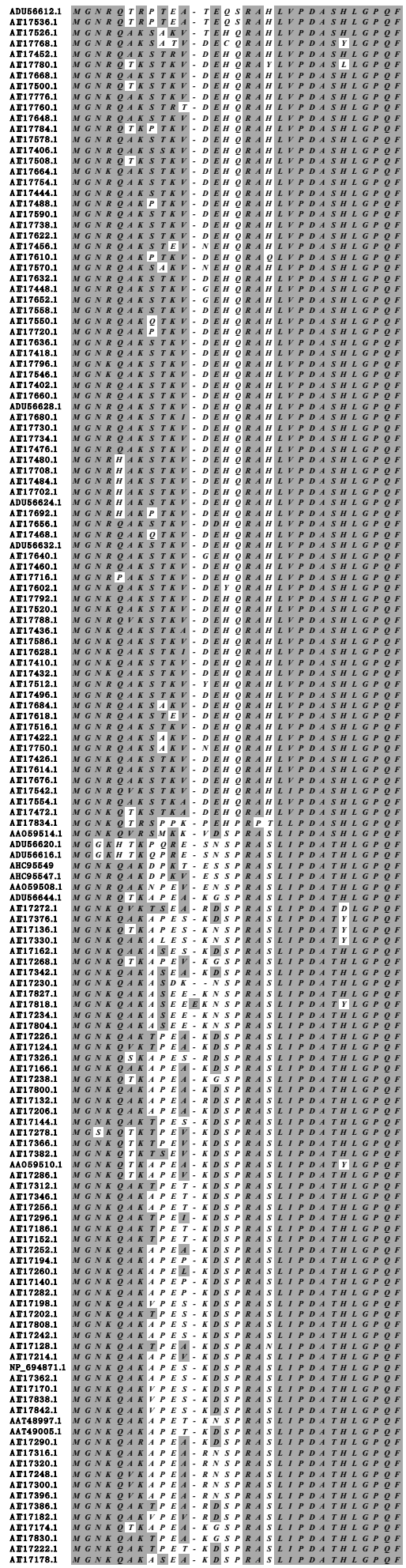

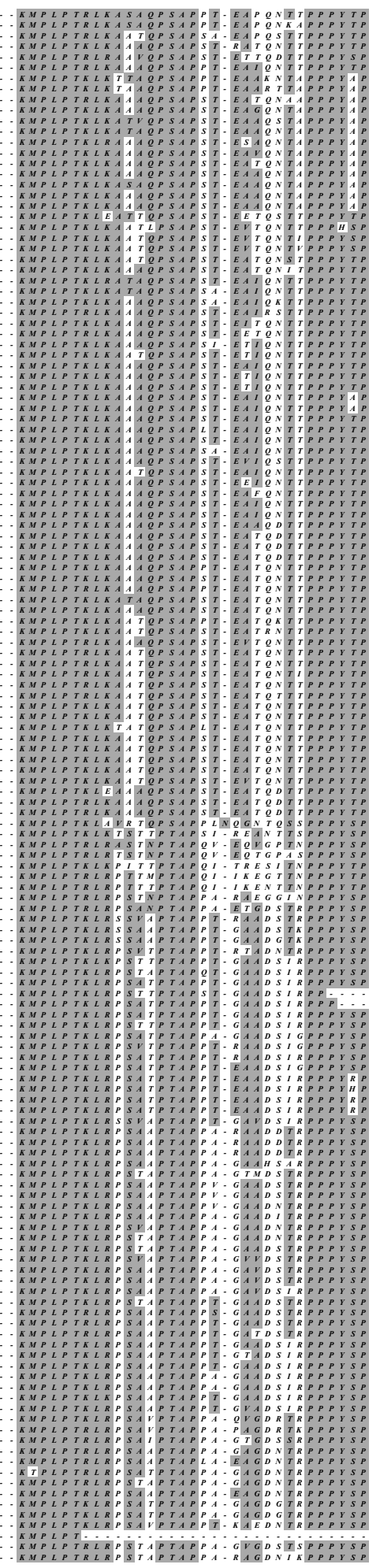

B.

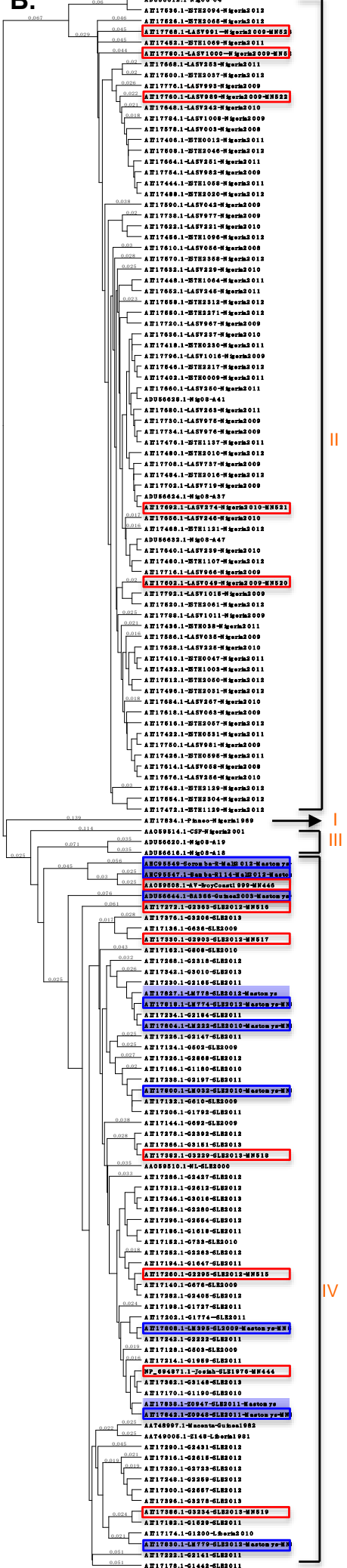

Figure 1. Sequence alignment and phylogenetic analysis of LASV Z proteins. (A) The Z protein amino acid sequences obtained from the GenBank database were aligned, with the N-terminal domain (NTD) 
and the C-terminal domain (CTD) sequences shown. Sequences of the conserved central RING domain are represented as short dash lines. (B) The phylogenetic tree based on the amino acid sequences of $\mathrm{Z}$ proteins. LASV isolates from rodents (Mastomys natalensis) are shown in blue shade. Z proteins analyzed in this study are outlined, those from human viral isolates shown in red boxes and those from rodent viral isolates in blue boxes.

\subsection{Establishment of a Convenient and Quantitative Assay to Evaluate RIG-I Inhibition by Z Proteins}

RLRs such as RIG-I and MDA5 are the major sensors of intracellular RNA virus infection to activate the downstream signaling pathway in order to induce the expression of IFN-I and other proinflammatory cytokines, which together mediate an antiviral response [13]. As such RLRs and their signaling pathways are the frequent targets of viral immune evasion. We have previously shown that $\mathrm{Z}$ proteins of pathogenic arenaviruses (e.g., LASV) but not of non-pathogenic arenaviruses (e.g., PICV) can bind to RIG-I and inhibit RLR activation [18]. In order to quantitatively evaluate the ability of the $Z$ protein to inhibit RIG-I function, we used an established human RIG-I-induced IFN $\beta$-LUC reporter assay [28]. Briefly, 293T cells were transfected with a plasmid expressing the $\mathrm{N}$ terminal domain of the human RIG-I (hRIG-I-N), which is a constitutively activated form of hRIG-I, and a plasmid that expresses the luciferase (LUC) reporter gene under the regulatory DNA element of the IFN $\beta$ promoter (IFN $\beta$-LUC), along with different amounts of the Z protein-expression plasmid. As shown in Figure $2 \mathrm{~A}$, under these experimental conditions, LASV (Josiah) Z protein strongly inhibited LUC expression in a dose-dependent manner, which was in sharp contrast to the negative control PICV Z protein that did not significantly reduce the LUC gene expression even at the highest concentration of PICV Z used. The amount of LASV (Josiah) Z plasmid required to reduce LUC gene expression by $50 \%$ (IC50) is $110 \mathrm{ng}$ and that for PICV Z is $>1000 \mathrm{ng}$ (Figure 2B), which are consistent with our previous report that LASV but not PICV Z can strongly inhibit human RLRs [18]. As the IC50 value is inversely correlated with the ability of the $Z$ protein to inhibit RIG-I function, it can be used to quantitatively evaluate the ability of $Z$ proteins to mediate hRIG-I inhibition.

\subsection{Evaluation of the Ability of Z Proteins of Different LASV Isolates to Inhibit hRIG-I Function}

As significant sequence variations exist among LASV Z proteins (Figure 1), we asked whether they can impact the ability of LASV Z proteins to inhibit hRIG-I function. To do this, we selected 20 LASV Z proteins that broadly represent the range of sequence variations, chemically synthesized the genes, and cloned them into the pCAGGS mammalian expression plasmid, each with a C-terminal HA tag. These include all nine aforementioned LASV isolates from rodents that belong to cluster IV (Figure 1B, blue box) and 11 randomly selected human LASV isolates from clusters II and IV (Figure 1B, red box). These $\mathrm{Z}$ proteins expressed at similar levels in transfected 293T cells as evidenced by Western blotting results using the anti-HA antibody (Figure 3A).

The ability of each of these $\mathrm{Z}$ proteins to inhibit hRIG-I function was examined in the established IFN- $\beta$ promoter-LUC reporter assay as described in Figure 2. The LASV (Josiah) $Z$ protein was included in each set of the experiments as a reference and a positive control. As shown in Figure 3A, all 20 LASV Z proteins tested could inhibit hRIG-I function in a dose-dependent manner. IC50 was calculated for each of the LASV Z proteins tested. The strongest inhibition is by LASV Z (accession ID AIT17272.1) from a human isolate in Sierra Leone, while the lowest inhibition is by LASV Z (accession ID AIT17808.1) from a Mastomys isolate in Sierra Leone (Figure 3A). The IC50 values of Z proteins from rodent (Mastomys) LASV isolates were on the average higher than those from human LASV isolates (Figure 3B). As the rodent LASV isolates exclusively belong to cluster IV, while the human LASV isolates belong to clusters II and IV, we decided to compare Z proteins from cluster IV only in order to exclude the potential confounding effect of cluster-specific LASV Z sequence variations. The IC50 values of LASV Z proteins from rodents (Mastomys) viral isolates were still higher than those from human LASV isolates of the same cluster IV (Figure 3C). As cluster IV includes isolates from several countries west of Nigeria, we compared only those Z proteins from LASV isolates in Sierra Leone and 
similarly found higher IC50 values associated with Z proteins of rodent LASV isolates than those of human LASV isolates (Figure 3D). However, when comparing human LASV isolates between clusters II and IV, we did not detect a significant difference in IC50 values (Figure 3E). These results suggest that $\mathrm{Z}$ proteins of human LASV isolates are on average stronger inhibitors of hRIG-I than those of LASV isolates found in the natural rodent reservoir (Mastomys).

A. hRIGi-induced IFN $\beta$-LUC reporter assay

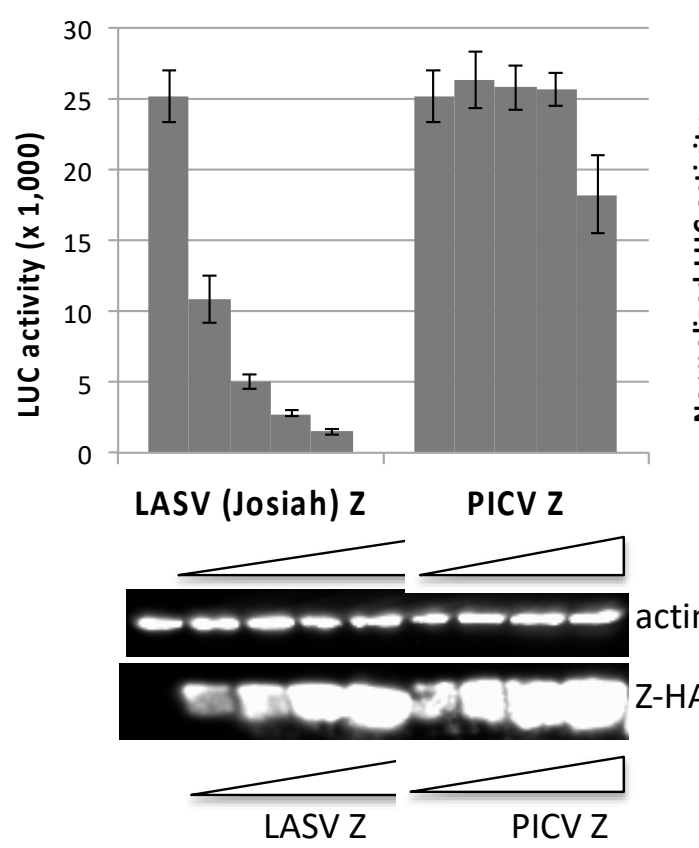

B. hRIGi-induced IFN $\beta$-LUC reporter assay

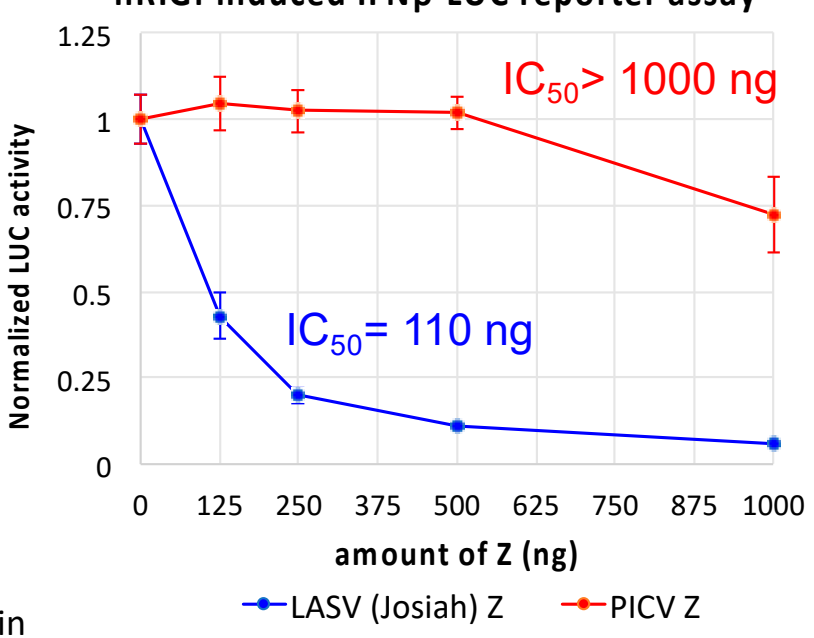

Figure 2. Comparative hRIG-I inhibitory analysis of LASV (Josiah) and PICV Z proteins. The effects of either LASV (Josiah) or PICV Z protein (in a dose-dependent manner) to inhibit the human RIG-I-N-induced IFN $\beta$ promoter-driven LUC reporter gene expressions were measured. 293T cells were transfected with a combination of plasmids ( $\mathrm{pEF-RIG-I-N,} \mathrm{IFN} \beta$-LUC reporter plasmid, and a $\beta$-Gal expression plasmid) together with either an empty vector or an increasing concentration of the $Z$ expression plasmid. LUC reporter activity was measured at $24 \mathrm{~h}(\mathrm{~A})$ and normalized by that in empty vector control (B). The expression of $Z$ proteins in the cells was detected by a Western blot analysis using an anti-HA antibody. $\mathrm{IC}_{50}$ value was determined by the amount of the $\mathrm{Z}$ plasmid required to reduce the LUC reporter activity by $50 \%$. Each plasmid transfection experiment was conducted in triplicate and repeated in at least two independent experiments.

\subsection{Evaluation of the Ability of Z Proteins of Different LCMV Strains to Inhibit hRIG-I Function}

As shown from the above studies, strain variations in the LASV Z protein can modulate its function to inhibit hRIG-I. We wish to extend these findings to another arenavirus, LCMV, with known genetic diversity [29,30]. With a natural reservoir in the house mouse Mus musculus, LCMV has a global distribution and causes zoonotic infections that are generally non-symptomatic or mild, but in some cases, result in neurological disorders, spontaneous abortion, congenital defects, and transplant-associated death [31]. Many LCMV strains have been isolated from human patients and rodents, with extensive genetic and phenotypic differences [30]. The Armstrong (Arm) strain was first isolated from an infected patient and has been passaged and used in many laboratories to infect mice for use as an acute viral infection model [32]. The Clone 13 (C13) strain was derived from the Armstrong strain but causes persistent infection in mice [33]. The Traub strain was isolated from a persistently infected mouse in 1935 [34,35]. The WE strain was isolated from an infected patient [36]. The MaTu-Mx $(\mathrm{Mx})$ strain was a new LCMV strain isolated from the MaTu cell line that was presumably derived from a human mammary tumor [37]. The M1 strain was isolated from mice in Japan [38]. The LCMV strain 
810935 was derived from human cerebral spinal fluid (CSF) [39]. The Douglas strain was isolated from a human patient [39]. Both the Docile and Aggressive strains of LCMV were derivatives of the parental UBC strain, with Docile causing a persistent infection and Aggressive causing an acute infection in mice [40]. Alignment of these LCMV Z proteins reveals significant sequence variations in the N-terminal domain (NTD) (Figure 4A), and a phylogenetic tree for them was generated (Figure 4B). We previously analyzed the Z protein of LCMV (Arm) for its functional significance to inhibit hRIG-I [18], and decided to compare it to another three LCMV Z proteins. The four LCMV Z proteins, from strains Armstrong (Aim), WE, Mx, and 810935, expressed well in cells after transient transfection. All of them could inhibit hRIG-I in a dose-dependent manner in the established IFN $\beta$ promoter-LUC assay (Figure 4C). The inhibitory effect of these LCMV Z proteins is similar between the Arm (IC50 = $220 \mathrm{ng}$ ) and WE (IC50 = $250 \mathrm{ng}$ ) strains, and stronger for 810935 (IC50 = 110 ng) and Mx (IC50 < $125 \mathrm{ng}$ ) strains (Figure 4C). These results suggest that, similar to LASV Z, strain variations exist among the different LCMV Z proteins and can impact the efficiency of innate immune inhibition.

A.
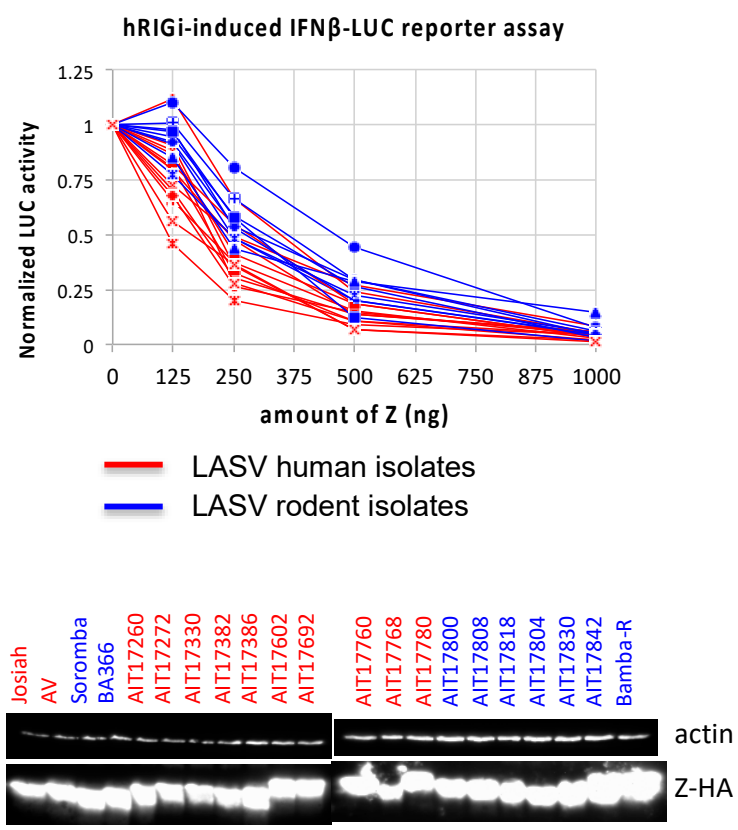

B. Z Inhibition of IFN $E$ UC

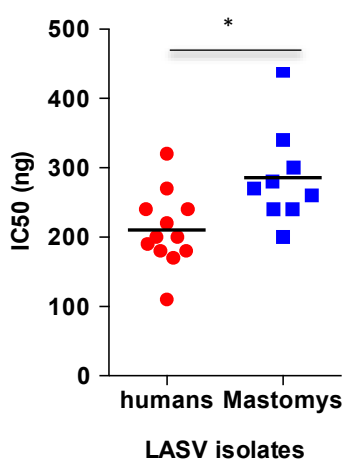

D. $\mathrm{Z}$ Inhibition of IFN $\beta \notin U C$

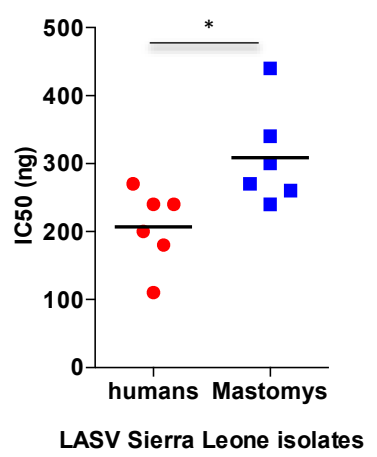

C. $\quad Z$ Inhibition of IFN $\beta \sqcup U C$

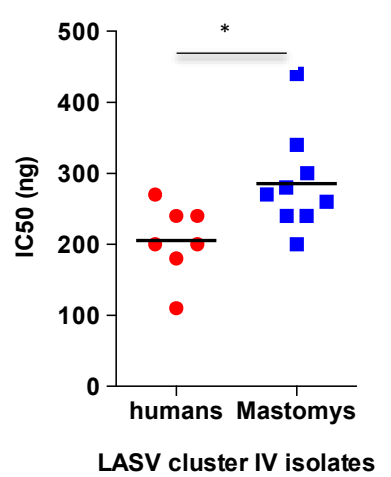

E. $\quad Z$ Inhibition of IFN $\_U C$

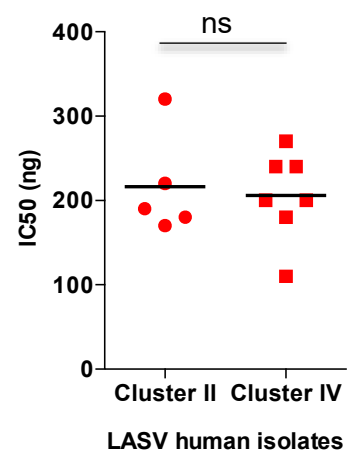

Figure 3. Comparative hRIG-I inhibitory analysis of $Z$ proteins from different LASV isolates. The hRIG-I inhibitory effects by the respective $Z$ proteins (in a dose-dependent manner) were determined as described above in the Figure 2 legend. (A) The normalized LUC activity by the empty vector control is shown for each $\mathrm{Z}$ protein in different doses. Western blot analysis of the tested LASV Z proteins is shown, with those from human viral isolates in red and those from rodent viral isolates in blue. Notable differences in the size of the $\mathrm{Z}$ proteins correspond to differences in their primary amino acid sequences. $\mathrm{IC}_{50}$ values were determined by the amount of the $\mathrm{Z}$ plasmid required to reduce the LUC reporter activity by $50 \%$ and are compared between $Z$ proteins of human and rodent viral isolates (B), between $\mathrm{Z}$ proteins of human and rodent viral isolates within the same cluster IV $(\mathrm{C})$, between $\mathrm{Z}$ proteins of human and rodent viral isolates within the same country (Sierra Leone) (D), and between Z proteins of human viral isolates between clusters II and IV (E). Each plasmid transfection experiment was conducted in triplicate and repeated in at least two independent experiments. Statistical significance between two groups was determined using the two-tail unpaired Student's $t$-test of GraphPad Prism 6 software. Statistical significance: $\mathrm{ns}$, not significant; ${ }^{*}, p<0.05$. 
A.

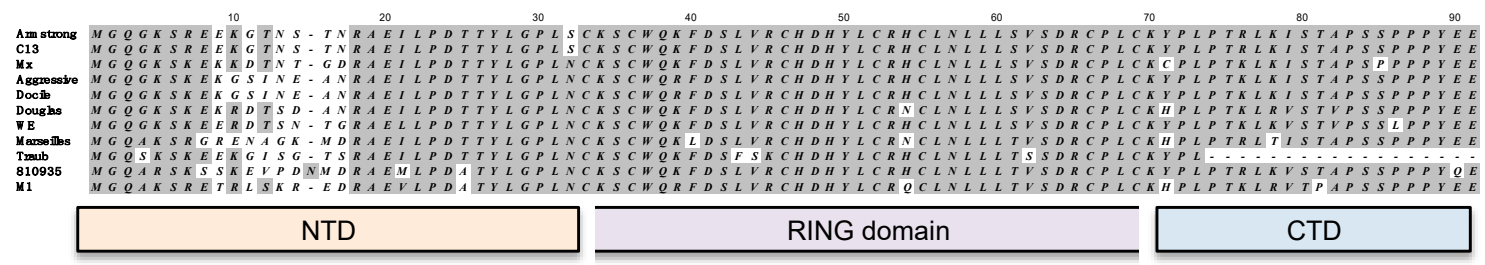

B.

Method: UPGMA; Best Tree; tie breaking $=$ System ati
Distance: Uncorrected ("p")

(ncontected (p)

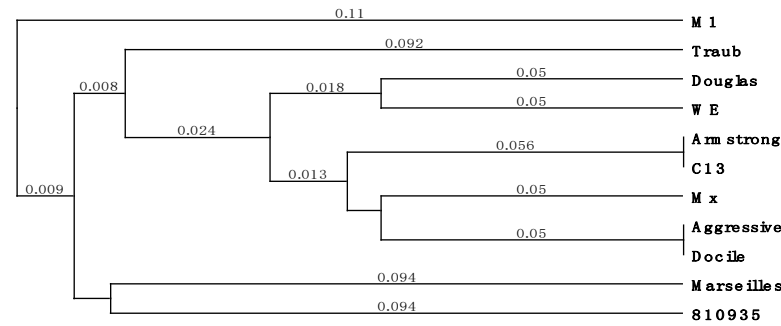

0.02
C.

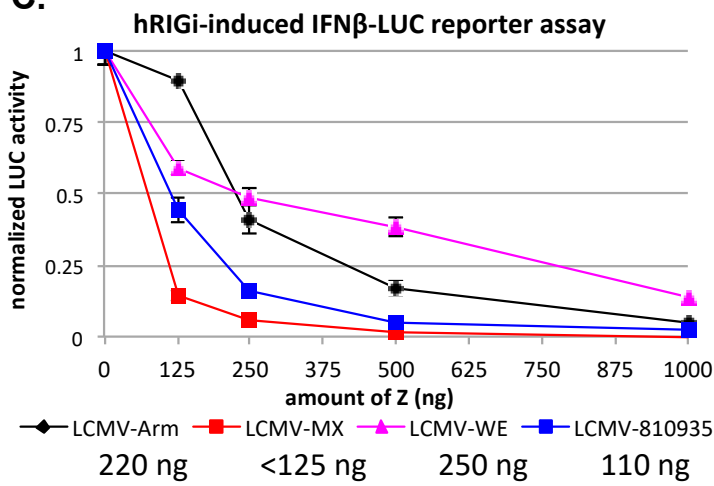

Figure 4. Comparative hRIG-I inhibitory analysis of $Z$ proteins from different LCMV strains. (A) The amino acid sequences of $Z$ proteins from different LCMV strains, Armstrong (P18541.3), cl13 (ABC96003), Mx (CAA10342), Aggressive (ACA61299), Docile (ACA61303), Douglas (ACV72588), WE, Marseille \#12 (ABB88930), Traub (P19325, partial sequence), 810935(ACV72580), and M1 (BAJ52729) were aligned using the MacVector software, with the N-terminal domain (NTD), the central RING domain, and the C-terminal domain (CTD) shown at the bottom. (B) The phylogenetic tree based on the amino acid sequences of $Z$ proteins. (C) Comparative hRIG-I inhibitory effects by the respective $\mathrm{Z}$ proteins (in a dose-dependent manner) of four different LCMV strains (Armstrong, WE, Mx, and 810935] were determined as described in the legend of Figure 2. Notable differences in the size of the $Z$ proteins correspond to differences in their primary amino acid sequences. The $\mathrm{IC}_{50}$ values for each of the LCMV Z proteins tested are shown in the figure legend. Western blot analysis of LCMV Z proteins is shown.

\section{Discussion}

LASV isolates display high levels of genetic diversity with nucleotide variations up to $32 \%$ for the L genomic segments, in sharp contrast to the Ebola viral genome, which is $>97 \%$ conserved among the sequenced viral isolates and strains [10]. The high levels of genetic diversity among LASV isolates may increase the complexity of viral virulence and disease pathogenesis and present significant challenges in developing effective vaccines and antiviral treatments [30,41]. LASV isolates found in their natural hosts Mastomys natalensis cluster together with those isolated from human patients in the same geographical locations, and do not form host-specific clusters [10]. These findings suggest that LASV originated in Nigeria and has spread into western African countries and that the common route of LASV transmissions in humans is mostly rodent-to-human and not human-to-human [10]. Nonsynonymous intra-host protein sequence variations have been found to accumulate in the predicted epitopes of the GPC protein and the variant alleles can significantly reduce GPC binding to the GP1-specific monoclonal antibodies [10], suggesting the strong selective pressure of host antibody response. Another study reveals a major positive selection pressure in the L polymerase protein and/or the NP protein 
of LASV (and LCMV), indicating both proteins, which make up the core viral polymerase complex, as possible determinant factors of LASV disease severity in humans [42]. However, the roles of viral genetic diversity in LASV virulence and disease pathogenesis have not been fully characterized, especially in a carefully controlled experimental setting.

Despite its small size, the $\mathrm{Z}$ protein carries out multiple functions at various steps of the viral life cycle and mediates virus-host interactions through its distinct structural features, which includes an invariable G2 myristoylation site, a highly variable NTD, a conserved central RING domain, and a CTD containing late domain(s) (reviewed in [43]). Z regulates viral RNA synthesis by interacting directly with the L polymerase protein through its central RING domain to block the viral polymerase catalytic activity [23,44-47]. $\mathrm{Z}$ is a key regulator of virion assembly through its $\mathrm{G} 2$ site-dependent interaction with viral envelop complex GPC [48], and its RING-domain-dependent interaction with viral ribonucleoprotein (vRNP) components $\mathrm{L}$ and NP [46,49-51]. $\mathrm{Z}$ is the major driving force for virion budding by recruiting proteins of the cellular ESCRT complexes, Tsg101 and Nedd4, through its C-terminal Late domain(s) $[23,52,53]$. In addition, $\mathrm{Z}$ has been found to interact with multiple cellular factors, such as the promyelocytic leukemia protein (PML), ribosomal proteins, and the eukaryotic translation initiation factor 4E (eIF4E), through its central RING domain [54-56]. Lastly, Z from pathogenic viruses (e.g., LASV and LCMV) has been shown to interact with hRIG-I through its NTD to inhibit IFN-I induction [18,57].

The $\mathrm{Z}$ protein has so far been excluded from the evolutionary genetic analysis partly due to its relatively small size ( $\sim 99$ amino acid residues) and its fast-evolving nature [42]. Significant sequence variations occur at both the NTD (residues 8-18) and the CTD (residues 77-93) of LASV Z proteins (Figure 1A), and mostly at the NTD (residues 9-16) of LCMV Z strains (Figure 4A), suggesting that these regions are less likely to be involved in essential activities of the viral life cycle but may potentially affect the function of $Z$ in mediating virus-host interactions with opportunistic hosts such as humans, for example, its interaction with hRIG-I to inhibit induction of IFN-I expression.

In the current study, we examined the potential effects of strain variations within the LASV Z proteins on their ability to inhibit hRIG-I function. We were particularly interested in addressing the question of whether Z proteins of the human LASV isolates show stronger inhibitory effect on hRIGI than those found in the rodent reservoir. As there were limited numbers of full-length $Z$ protein sequences from LASV rodent isolates available at GenBank and all of them were from cluster IV, we decided to include almost all of them in the analysis. We selected seven $\mathrm{Z}$ proteins from human viral isolates in clusters IV, some isolated from the same country in western Africa (Sierra Leone), for a better comparison to rodent viral isolates, as well as five from human viral isolates in cluster II to represent those with the most diversified sequence variations. We showed that all LASV Z proteins tested can inhibit hRIG-I function (Figure 2A), regardless of their host species or geographical locations, confirming our previous findings [18] that inhibition of hRIG-I is a conserved feature among LASV Z proteins. Notably, $Z$ proteins from human viral isolates show a slightly stronger inhibitory effect of hRIG-I on the average than those from rodent viral isolates, even when the comparison is made among viral isolates within the same cluster IV or those in the same country (Sierra Leone) (Figure 2B-D). No significant difference was detected for $\mathrm{Z}$ proteins of human viral isolates between cluster II and IV (Figure 2E), despite the fact that the inter-cluster sequence variations are larger than the intra-cluster variations. Although limited by a relatively small sampling size and a limited number of $Z$ sequences available for those viruses isolated from Mastomys rodents, our results suggest that sequence variations of LASV Z proteins in a genetically diverse pool of viruses in the rodent hosts can affect their ability to mediate hRIG-I inhibition and that a stronger inhibition of hRIG-I may give the virus an advantage when infecting humans. As the majority of human LASV transmissions are mainly the result of the rodent-to-human and not the human- to- human route [10], viral evolution is thought to be largely determined by events occurring in the rodent reservoirs [42]. However, it remains to be determined whether LASV isolates from rodent reservoirs in other viral clusters (I to III) exhibit any differences in their ability to mediate hRIG-I inhibition, which requires a large-scale sequencing effort to survey 
LASV pools in rodent reservoirs. Furthermore, little has been known about the mechanisms of innate immunity in Mastomys and other natural rodent reservoirs of LASV, and an experimental system is lacking to directly address these important questions. Laboratory mice are of different rodent species and do not persistently shed virus upon LASV infection ([58], reviewed in [19]). As such, we are unable to determine whether LASV Z inhibits innate immunity of their natural rodent hosts in a similar manner or mechanism as seen in humans and whether and how strain variations of the $Z$ protein or other viral proteins may affect LASV interactions within the natural rodent hosts. These are outstanding questions that still need to be addressed to understand LASV evolution and transmission toward the development of effective counter measures to reduce the risk of LASV transmissions in endemic areas.

It is worth noting that, in addition to the Z protein, LASV contains another IFN-I antagonist-the NP protein - which blocks the IFN-I induction through its conserved $3^{\prime}-5^{\prime}$ exoribonuclease (RNase) activity $[15,16,59]$. Recombinant LASV with NP RNase mutants are severely defective in the suppression of IFN-Is in macrophages and dendritic cells [60], demonstrating the importance of LASV NP RNase activity in the IFN-I inhibition. The respective roles of LASV NP RNase and Z in the IFN-I inhibition have not been formally and carefully examined using individual and combined mutations, nor have their roles in host innate suppression and viral virulence been examined in vivo. In contrast to LASV, New World pathogenic arenaviruses, such as Junin and Machupo, induce high level of IFN-Is in the virus-infected cells [61], even though they both have functional NP RNase activity that can strongly inhibit the IFN-I induction in the cell-based gene expression system [59,62], highlighting the complexity of different virus and model systems used in the analysis. In addition, the distinct disease outcomes of LASV infections in humans and in animals suggest a species-specific difference in host innate immunity and its modulation by LASV. Taken together, how IFN-Is are regulated at molecular, cellular, and organismal levels during LASV infections needs to be carefully evaluated, using experimental settings that closely mimic human infections.

\title{
5. Conclusions
}

In summary, our study examines the effect of strain variations within LASV Z proteins from different human and rodent isolates to inhibit hRIG-I function that can provide important insights into the role of the $\mathrm{Z}$ protein as a virulence factor to mediate host immune evasion upon human LASV infections. Understanding how LASV sequence variations affect the function of viral gene products and host immune responses is critical for understanding disease heterogeneity and for the development of effective vaccines and antivirals with a broad protection against different LASV natural isolates [41].

Author Contributions: Conceptualization, H.L. and Y.L.; methodology, Q.H. and X.L.; software, Y.L.; validation, Q.H., X.L. and M.B.; formal analysis, Y.L.; investigation, Q.H., X.L., M.B., H.L., and Y.L.; resources, H.L. and Y.L.; data curation, Q.H. and X.L.; writing—original draft preparation, Y.L.; writing-review and editing, H.L. and Y.L.; visualization, Y.L.; supervision, H.L. and Y.L.; project administration, H.L. and Y.L.; funding acquisition, H.L. and Y.L. All authors have read and agreed to the published version of the manuscript.

Funding: This research was funded by National Institute of Health (NIH), grant number R01 AI131586 to H.L. and Y.L. M.B. was supported in part by a NIH pre-doctoral T32 fellowship DA007097.

Acknowledgments: We thank Takashi Fujita (Kyoto University, Japan) for providing the pEF-Flag-RIG-I-N expression plasmid.

Conflicts of Interest: The authors declare no conflict of interest.

\author{
Abbreviations \\ LCMV lymphocytic choriomeningitis virus \\ LASV Lassa virus \\ IFN-I type I interferon \\ LUC luciferase \\ $\mathrm{NP}$ nucleoprotein \\ GPC glycoprotein precursor complex
}




$\begin{array}{ll}\text { RNP } & \text { ribonucleoprotein } \\ \text { RNase } & \text { exoribonuclease } \\ \text { RLRs } & \text { RIG-I-like receptors } \\ \text { NHPs } & \text { non-human primates } \\ \text { PICV } & \text { Pichinde virus } \\ \text { Fluc } & \text { firefly luciferase } \\ \text { ECL } & \text { enhanced chemiluminescence } \\ \text { NTD } & \text { N-terminal domain } \\ \text { CTD } & \text { C-terminal domain } \\ \text { CSF } & \text { cerebral spinal fluid }\end{array}$

\section{References}

1. Johnson, K.M.; McCormick, J.B.; Webb, P.A.; Smith, E.S.; Elliott, L.H.; King, I.J. Clinical Virology of Lassa Fever in Hospitalized Patients. J. Infect. Dis. 1987, 155, 456-464. [CrossRef]

2. McCormick, J.B.; Webb, P.A.; Krebs, J.W.; Johnson, K.M.; Smith, E.S. A Prospective Study of the Epidemiology and Ecology of Lassa Fever. J. Infect. Dis. 1987, 155, 437-444. [CrossRef]

3. Olayemi, A.; Cadar, D.; Magassouba, N.; Obadare, A.; Kourouma, F.; Oyeyiola, A.; Fasogbon, S.; Igbokwe, J.; Rieger, T.; Bockholt, S.; et al. New Hosts of The Lassa Virus. Sci. Rep. 2016, 6, 25280. [CrossRef]

4. Olayemi, A.; Oyeyiola, A.; Obadare, A.; Igbokwe, J.; Adesina, A.S.; Onwe, F.; Ukwaja, K.N.; Ajayi, N.; Rieger, T.; Günther, S.; et al. Widespread arenavirus occurrence and seroprevalence in small mammals, Nigeria. Parasites Vectors 2018, 11, 416. [CrossRef]

5. McCormick, J.B.; Fisher-Hoch, S.P. Lassa Fever. Curr. Top. Microbiol. Immunol. 2002, 262, 75-109. [CrossRef]

6. McCormick, J.B.; King, I.J.; Webb, P.A.; Johnson, K.M.; O'Sullivan, R.; Smith, E.S.; Trippel, S.; Tong, T.C. A Case-Control Study of the Clinical Diagnosis and Course of Lassa Fever. J. Infect. Dis. 1987, 155, 445-455. [CrossRef]

7. Fisher-Hoch, S.P.; Tomori, O.; Nasidi, A.; Perez-Oronoz, G.I.; Fakile, Y.; Hutwagner, L.; McCormick, J.B. Review of cases of nosocomial Lassa fever in Nigeria: The high price of poor medical practice. BMJ 1995, 311, 857-859. [CrossRef]

8. WHO Lassa Fever-Nigeria, Disease Outbreak News. Available online: https://www.who.int/csr/don/14february-2019-lassa-fever-nigeria/en/ (accessed on 19 June 2020).

9. Bowen, M.D.; Rollin, P.E.; Ksiazek, T.G.; Hustad, H.L.; Bausch, D.G.; Demby, A.H.; Bajani, M.D.; Peters, C.J.; Nichol, S.T. Genetic Diversity among Lassa Virus Strains. J. Virol. 2000, 74, 6992-7004. [CrossRef]

10. Andersen, K.G.; Shapiro, B.J.; Matranga, C.; Sealfon, R.; Lin, A.E.; Moses, L.M.; Folarin, O.A.; Goba, A.; Odia, I.; Ehiane, P.E.; et al. Clinical Sequencing Uncovers Origins and Evolution of Lassa Virus. Cell 2015, 162, 738-750. [CrossRef]

11. Buchmeier, M.J.; De La Torre, J.C.; Peters, C.J. Arenaviridae. In Fields Virology, 5th ed.; Knipe, D.M., Howley, P.M., Eds.; Lippincott Williams \& Wilkins: Philadelphia, PA, USA, 2013; pp. 1283-1303.

12. Shao, J.; Liang, Y.; Ly, H. Human Hemorrhagic Fever Causing Arenaviruses: Molecular Mechanisms Contributing to Virus Virulence and Disease Pathogenesis. Pathogens 2015, 4, 283-306. [CrossRef]

13. Brisse, M.; Ly, H. Hemorrhagic Fever-Causing Arenaviruses: Lethal Pathogens and Potent Immune Suppressors. Front. Immunol. 2019, 10, 372. [CrossRef]

14. McLay, L.; Ansari, A.; Liang, Y.; Ly, H. Targeting virulence mechanisms for the prevention and therapy of arenaviral hemorrhagic fever. Antivir. Res. 2013, 97, 81-92. [CrossRef]

15. Qi, X.; Lan, S.; Wang, W.; Schelde, L.M.; Dong, H.; Wallat, G.D.; Ly, H.; Liang, Y.; Dong, C. Cap binding and immune evasion revealed by Lassa nucleoprotein structure. Nature 2010, 468, 779-783. [CrossRef]

16. Hastie, K.M.; Kimberlin, C.R.; Zandonatti, M.A.; Macrae, I.J.; Saphire, E.O. Structure of the Lassa virus nucleoprotein reveals a dsRNA-specific $3^{\prime}$ to $5^{\prime}$ exonuclease activity essential for immune suppression. Proc. Natl. Acad. Sci. USA 2011, 108, 2396-2401.

17. Meyer, B.; Ly, H. Inhibition of Innate Immune Responses Is Key to Pathogenesis by Arenaviruses. J. Virol. 2016, 90, 3810-3818. [CrossRef]

18. Xing, J.; Ly, H.; Liang, Y. Correction for Xing et al., The Z Proteins of Pathogenic but Not Nonpathogenic Arenaviruses Inhibit RIG-i-Like Receptor-Dependent Interferon Production. J. Virol. 2015, 89, 6161. [CrossRef] 
19. Sattler, R.A.; Paessler, S.; Ly, H.; Huang, C. Animal Models of Lassa Fever. Pathogens 2020, 9, 197. [CrossRef]

20. Jahrling, P.B.; Frame, J.D.; Smith, S.B.; Monson, M.H. Endemic Lassa fever in Liberia. III. Characterization of Lassa virus isolates. Trans. R. Soc. Trop. Med. Hyg. 1985, 79, 374-379. [CrossRef]

21. Yun, N.E.; Ronca, S.; Tamura, A.; Koma, T.; Seregin, A.V.; Dineley, K.T.; Miller, M.; Cook, R.; Shimizu, N.; Walker, A.G.; et al. Animal Model of Sensorineural Hearing Loss Associated with Lassa Virus Infection. J. Virol. 2015, 90, 2920-2927. [CrossRef]

22. Safronetz, D.; Strong, J.E.; Feldmann, F.; Haddock, E.; Sogoba, N.; Brining, D.; Geisbert, T.W.; Scott, D.P.; Feldmann, H. A Recently Isolated Lassa Virus from Mali Demonstrates Atypical Clinical Disease Manifestations and Decreased Virulence in Cynomolgus Macaques. J. Infect. Dis. 2013, 207, 1316-1327. [CrossRef]

23. Wang, J.; Danzy, S.; Kumar, N.; Ly, H.; Liang, Y. Biological Roles and Functional Mechanisms of Arenavirus Z Protein in Viral Replication. J. Virol. 2012, 86, 9794-9801. [CrossRef]

24. Djavani, M.; Lukashevich, I.S.; Sanchez, A.; Nichol, S.T.; Salvato, M.S. Completion of the Lassa fever virus sequence and identification of a RING finger open reading frame at the L RNA 5' End. Virology 1997, 235, 414-418.

25. Vieth, S.; Torda, A.E.; Asper, M.; Schmitz, H.; Günther, S. Sequence analysis of L RNA of Lassa virus. Virology 2004, 318, 153-168. [CrossRef]

26. Ehichioya, D.U.; Hass, M.; Becker-Ziaja, B.; Ehimuan, J.; Asogun, D.; Fichet-Calvet, E.; Kleinsteuber, K.; Lelke, M.; Ter Meulen, J.; Akpede, G.O.; et al. Current Molecular Epidemiology of Lassa Virus in Nigeria. J. Clin. Microbiol. 2010, 49, 1157-1161. [CrossRef]

27. Safronetz, D.; Sogoba, N.; López, J.E.; Maïga, O.; Dahlstrom, E.; Zivcec, M.; Feldmann, F.; Haddock, E.; Fischer, R.J.; Anderson, J.M.; et al. Geographic Distribution and Genetic Characterization of Lassa Virus in Sub-Saharan Mali. PLoS Negl. Trop. Dis. 2013, 7, e2582. [CrossRef]

28. Huang, Q.; Shao, J.; Lan, S.; Zhou, Y.; Xing, J.; Dong, C.; Liang, Y.; Ly, H. In vitro and in vivo characterizations of the Pichinde viral NP exoribonuclease function. J. Virol. 2015, 89, 6595-6607.

29. Sevilla, N.; De La Torre, J.C. Arenavirus Diversity and Evolution: Quasispecies In Vivo. Curr. Top. Microbiol. Immunol. 2006, 299, 315-335. [CrossRef]

30. Grande-Pérez, A.; Martin, V.; Moreno, H.; De La Torre, J.C. Arenavirus Quasispecies and Their Biological Implications. Curr. Top. Microbiol. Immunol. 2016, 392, 231-276.

31. Bonthius, D.J. Lymphocytic choriomeningitis virus: An underrecognized cause of neurologic disease in the fetus, child, and adult. Semin. Pediatr. Neurol. 2012, 19, 89-95. [CrossRef]

32. Abdel-Hakeem, M.S. Viruses Teaching Immunology: Role of LCMV Model and Human Viral Infections in Immunological Discoveries. Viruses 2019, 11, 106. [CrossRef]

33. Ahmed, R.; Oldstone, M.B. Organ-specific selection of viral variants during chronic infection. J. Exp. Med. 1988, 167, 1719-1724. [CrossRef]

34. Traub, E. A FILTERABLE VIRUS RECOVERED FROM WHITE MICE. Science 1935, 81, 298-299. [CrossRef]

35. Takagi, T.; Ohsawa, M.; Yamanaka, H.; Matsuda, N.; Sato, H.; Ohsawa, K. Difference of two new LCMV strains in lethality and viral genome load in tissues. Exp. Anim. 2017, 66, 199-208. [CrossRef]

36. Rivers, T.M.; Scott, T.F.M. Meningitis in man caused by a filterable virus. Science 1935, 81, 439-440. [CrossRef]

37. Reiserová, L.; Kaluzová, M.; Kaluz, S.; Willis, A.C.; Závada, J.; Závodská, E.; Závadová, Z.; Čiampor, F.; Pastorek, J.; Pastoreková, S. Identification of MaTu-MX agent as a new strain of lymphocytic choriomeningitis virus (LCMV) and serological indication of horizontal spread of LCMV in human population. Virology 1999, 257,73-83. [CrossRef]

38. Ike, F.; Bourgade, F.; Ohsawa, K.; Sato, H.; Morikawa, S.; Saijo, M.; Kurane, I.; Takimoto, K.; Yamada, Y.K.; Jaubert, J.; et al. Lymphocytic choriomeningitis infection undetected by dirty-bedding sentinel monitoring and revealed after embryo transfer of an inbred strain derived from wild mice. Comp. Med. 2007, 57, $272-281$.

39. Albariño, C.G.; Palacios, G.; Khristova, M.L.; Erickson, B.R.; Carroll, S.A.; Comer, J.A.; Hui, J.; Briese, T.; George, K.S.; Ksiazek, T.G.; et al. High Diversity and Ancient Common Ancestry of Lymphocytic Choriomeningitis Virus. Emerg. Infect. Dis. 2010, 16, 1093-1100. [CrossRef]

40. Chen, M.; Lan, S.; Ou, R.; Price, G.E.; Jiang, H.; De La Torre, J.C.; Moskophidis, D. Genomic and biological characterization of aggressive and docile strains of lymphocytic choriomeningitis virus rescued from a plasmid-based reverse-genetics system. J. Gen. Virol. 2008, 89, 1421-1433. [CrossRef] 
41. Lukashevich, I.S.; Paessler, S.; De La Torre, J.C. Lassa virus diversity and feasibility for universal prophylactic vaccine. F1000Research 2019, 8, 134. [CrossRef]

42. Pontremoli, C.; Forni, D.; Cagliani, R.; Pozzoli, U.; Riva, S.; Bravo, I.; Clerici, M.; Sironi, M. Evolutionary analysis of Old World arenaviruses reveals a major adaptive contribution of the viral polymerase. Mol. Ecol. 2017, 26, 5173-5188. [CrossRef]

43. Fehling, S.K.; Lennartz, F.; Strecker, T. Multifunctional Nature of the Arenavirus RING Finger Protein Z. Viruses 2012, 4, 2973-3011. [CrossRef]

44. Cornu, T.I.; De La Torre, J.C. RING Finger Z Protein of Lymphocytic Choriomeningitis Virus (LCMV) Inhibits Transcription and RNA Replication of an LCMV S-Segment Minigenome. J. Virol. 2001, 75, 9415-9426. [CrossRef]

45. Cornu, T.I.; De La Torre, J.C. Characterization of the Arenavirus RING Finger Z Protein Regions Required for Z-Mediated Inhibition of Viral RNA Synthesis. J. Virol. 2002, 76, 6678-6688. [CrossRef]

46. Kranzusch, P.J.; Whelan, S.P.J. Arenavirus $Z$ protein controls viral RNA synthesis by locking a polymerase-promoter complex. Proc. Natl. Acad. Sci. USA 2011, 108, 19743-19748. [CrossRef]

47. Jácamo, R.; López, N.; Wilda, M.; Franze-Fernández, M.T. Tacaribe Virus Z Protein Interacts with the L Polymerase Protein to Inhibit Viral RNA Synthesis. J. Virol. 2003, 77, 10383-10393. [CrossRef]

48. Capul, A.A.; Perez, M.; Burke, E.; Kunz, S.; Buchmeier, M.J.; De La Torre, J.C. Arenavirus Z-Glycoprotein Association Requires Z Myristoylation but Not Functional RING or Late Domains. J. Virol. 2007, 81, 9451-9460. [CrossRef]

49. Eichler, R.; Strecker, T.; Kolesnikova, L.; Ter Meulen, J.; Weissenhorn, W.; Becker, S.; Klenk, H.D.; Garten, W.; Lenz, O. Characterization of the Lassa virus matrix protein Z: Electron microscopic study of virus-like particles and interaction with the nucleoprotein (NP). Virus Res. 2004, 100, 249-255. [CrossRef]

50. Schlie, K.; Maisa, A.; Freiberg, F.; Groseth, A.; Strecker, T.; Garten, W. Viral Protein Determinants of Lassa Virus Entry and Release from Polarized Epithelial Cells. J. Virol. 2010, 84, 3178-3188. [CrossRef]

51. Casabona, J.C.; MacLeod, J.M.L.; Loureiro, M.E.; A Gomez, G.; Lopez, N. The RING Domain and the L79 Residue of $Z$ Protein Are Involved in both the Rescue of Nucleocapsids and the Incorporation of Glycoproteins into Infectious Chimeric Arenavirus-Like Particles. J. Virol. 2009, 83, 7029-7039. [CrossRef]

52. Strecker, T.; Eichler, R.; Ter Meulen, J.; Weissenhorn, W.; Klenk, H.D.; Garten, W.; Lenz, O. Lassa virus Z protein is a matrix protein and sufficient for the release of virus-like particles [corrected]. J. Virol. 2003, 77, 10700-10705.

53. Perez, M.; Craven, R.C.; De La Torre, J.C. The small RING finger protein Z drives arenavirus budding: Implications for antiviral strategies. Proc. Natl. Acad. Sci. USA 2003, 100, 12978-12983. [CrossRef]

54. Borden, K.L.B.; Dwyer, E.J.C.; Salvato, M.S. An Arenavirus RING (Zinc-Binding) Protein Binds the Oncoprotein Promyelocyte Leukemia Protein (PML) and Relocates PML Nuclear Bodies to the Cytoplasm. J. Virol. 1998, 72, 758-766. [CrossRef]

55. Borden, K.L.B.; CampbellDwyer, E.J.; Carlile, G.W.; Djavani, M.; Salvato, M.S. Two RING Finger Proteins, the Oncoprotein PML and the Arenavirus Z Protein, Colocalize with the Nuclear Fraction of the Ribosomal P Proteins. J. Virol. 1998, 72, 3819-3826. [CrossRef]

56. Dwyer, E.J.C.; Lai, H.; Macdonald, R.C.; Salvato, M.S.; Borden, K.L.B. The Lymphocytic Choriomeningitis Virus RING Protein Z Associates with Eukaryotic Initiation Factor 4E and Selectively Represses Translation in a RING-Dependent Manner. J. Virol. 2000, 74, 3293-3300. [CrossRef]

57. Fan, L.; Briese, T.; Lipkin, W.I. Z Proteins of New World Arenaviruses Bind RIG-I and Interfere with Type I Interferon Induction. J. Virol. 2009, 84, 1785-1791. [CrossRef]

58. Vela, E.M. Animal Models, Prophylaxis, and Therapeutics for Arenavirus Infections. Viruses 2012, 4, 1802-1829. [CrossRef]

59. Martínez-Sobrido, L.; Zúñiga, E.I.; Rosario, D.; Garc1-a-Sastre, A.; De La Torre, J.C. Inhibition of the Type I Interferon Response by the Nucleoprotein of the Prototypic Arenavirus Lymphocytic Choriomeningitis Virus. J. Virol. 2006, 80, 9192-9199. [CrossRef]

60. Carnec, X.; Baize, S.; Reynard, S.; Diancourt, L.; Caro, V.; Tordo, N.; Bouloy, M. Lassa Virus Nucleoprotein Mutants Generated by Reverse Genetics Induce a Robust Type I Interferon Response in Human Dendritic Cells and Macrophages. J. Virol. 2011, 85, 12093-12097. [CrossRef] 
61. Huang, C.; Kolokoltsova, O.A.; Yun, N.E.; Seregin, A.V.; Ronca, S.; Koma, T.; Paessler, S. Highly Pathogenic New World and Old World Human Arenaviruses Induce Distinct Interferon Responses in Human Cells. J. Virol. 2015, 89, 7079-7088. [CrossRef]

62. Jiang, X.; Huang, Q.; Wang, W.; Dong, H.; Ly, H.; Liang, Y.; Dong, C. Structures of Arenaviral Nucleoproteins with Triphosphate dsRNA Reveal a Unique Mechanism of Immune Suppression. J. Biol. Chem. 2013, 288, 16949-16959. [CrossRef]

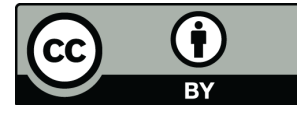

(C) 2020 by the authors. Licensee MDPI, Basel, Switzerland. This article is an open access article distributed under the terms and conditions of the Creative Commons Attribution (CC BY) license (http://creativecommons.org/licenses/by/4.0/). 